\title{
Estudio radiológico de cabritos suplementados con enrofloxacina
}

\author{
Galotta, M.L.; Moscuzza, C.H.; F.Cirelli, A.
}

Instit. Investig. Prod. Anim. (UBA-CONICET), Fac. Ciencias Veterinarias, Universidad de Buenos Aires, Argentina. E-mail: afcirelli@fvet.uba.ar

\section{Resumen}

Galotta, M.L.; Moscuzza, C.H.; F.Cirelli, A.: Estudio radiológico de cabritos suplementados con enrofloxacina. Rev. Vet. 30: 2, XX-XX, 2019. El uso de antibióticos en medicina veterinaria está asociado a la prevención y tratamiento de enfermedades infecciosas, así como a una acción promotora del crecimiento. En este contexto, la enrofloxacina es un antibiótico ampliamente utilizado. Por otro lado, la información del uso de esta droga en crías de pequeños rumiantes es escasa. El propósito de este trabajo fue evaluar radiograficamente a cabritos suplementados diariamente con enrofloxacina. Los animales fueron alimentados con leche en polvo de vaca, reconstituida con el agregado del antibiótico (5 mg/kg/día). A los 70 días de edad se realizó un estudio radiológico, utilizando un animal control para las comparaciones. El estudio demostró un marcado aumento en la densidad cortical y ósea de las articulaciones anteriores de los animales que consumieron la droga. Se encontró que el uso de este esquema de administración provocó alteraciones articulares en la especie caprina.

Palabras clave: cabras, fluoroquinolonas, articulaciones, rayos-X, aumento de la densidad ósea.

\begin{abstract}
Galotta, M.L.; Moscuzza, C.H.; F.Cirelli, A.: Radiological study of goat kids supplemented with enrofloxacin. Rev. Vet. 30: 2, $X X-X X$, 2019. Antibiotics in veterinary medicine are used not only for the prevention and treatment of infectious diseases, but also as growth promoters. In this context, enrofloxacin is an antibiotic widely used in veterinary medicine. On the other hand, information on the use of this drug in small ruminants is scarce. The purpose of this work was to perform a radiological study of goat kids submitted to a daily supplementation with enrofloxacin. The animals were fed with reconstituted cow's milk powder with the addition of the antibiotic ( $5 \mathrm{mg} / \mathrm{kg} / \mathrm{day}$ ). At 70 days of age, a radiological study was performed, using a control animal for comparisons. This study showed a marked increase in cortical and bone density of the thoracic joints of the animals that received the drug. It was found that the use of this scheme of administration caused joint alterations in the species. However, further investigations are required in order to find an adequate administration protocol that does not generate biomechanical alterations in growing animals.
\end{abstract}

Keywords: goats, fluoroquinolones, joints, X-rays, increase of bony density.

Recibido: agosto 2018 / Aceptado: octubre 2018

\section{INTRODUCCIÓN}

En Argentina, la crianza artificial de cabritos es una práctica empleada por un número creciente de establecimientos, en particular aquellos dedicados a la actividad del 
tambo. En general, las metodologías de crianza artificial implementadas se basan en recomendaciones locales que incluyen, en algunos casos, el uso de antibióticos no sólo para la prevención y tratamiento de enfermedades sino también por su efecto como promotores de crecimiento (Sustain Agri Food Environ Res 6: 2, 2014).

En la actualidad, uno de los antibióticos mayormente empleados es la enrofloxacina (una flouroquinolona), por su acción contra bacterias gram-negativas, grampositivas, anaerobios y Micoplasma $\mathrm{sp}^{1,2}$.

Estudios previos realizados en animales monogástricos han sugerido la existencia de una relación entre la administración de esta droga y la aparición de una artropatía erosiva no inflamatoria en animales en crecimiento ${ }^{3}$. Los estudios en rumiantes, y en particular en caprinos, son escasos y referidos a la farmacocinética y no a los efectos tóxicos sobre el animal ${ }^{4}$.

En tal contexto, el propósito de esta comunicación fue evaluar radiológicamente las articulaciones de animales suplementados de forma diaria con enrofloxacina.

\section{MATERIAL Y MÉTODOS}

La experiencia piloto se llevó a cabo en las instalaciones de la Facultad de Ciencias Veterinarias de la Universidad de Buenos Aires, bajo condiciones de bienestar animal (Comité institucional de cuidado y uso de animales de experimentación- CICUAL).

Se seleccionaron cuatro cabritos de la raza Anglo Nubian clasificados como sanos (sin anormalidades) para ser incorporados al estudio. Luego del nacimiento, los animales fueron separados de sus madres y alimentados con calostro los primeros dos días de vida.

El régimen de alimentación de tres animales consistió en el suministro de leche en polvo de vaca entera reconstituida (150 g de leche en polvo/litro de agua) a la que se le adicionó enrofloxacina a razón de $5 \mathrm{mg} / \mathrm{kg} /$ día (Enromax ${ }^{\circledR}$ Richmond) durante 42 días.

El cuarto animal (definido como control) fue alimentado sin el agregado del antibiótico. En todos los tratamientos la leche fue atemperada a $40^{\circ} \mathrm{C}$ y administrada dos veces al día mediante mamadera con tetina de goma (alrededor de 1,5 litros diarios).

Los animales fueron alojados en corrales con dimensión de $12 \mathrm{~m}^{2}$, piso de cemento y cama de paja de trigo o similar, con acceso a bebederos con agua ad libitum. A los $70 \pm 10$ días de vida se efectuaron radiologías de la articulación del carpo en las incidencias antero posterior y latero lateral de cada miembro anterior.

\section{RESULTADOS Y DISCUSIÓN}

Para las comparaciones radiológicas se tomaron como imágenes normales las correspondientes al animal control. En los animales suplementados con enrofloxacina se observó un marcado aumento en la densidad cortical y densidad ósea en forma generalizada; con un aumento del espesor y la densidad del área de esclerosis en la metáfisis distal de los húmeros, presentándose el borde proximal del área con márgenes poco definidos (Figura 1). 


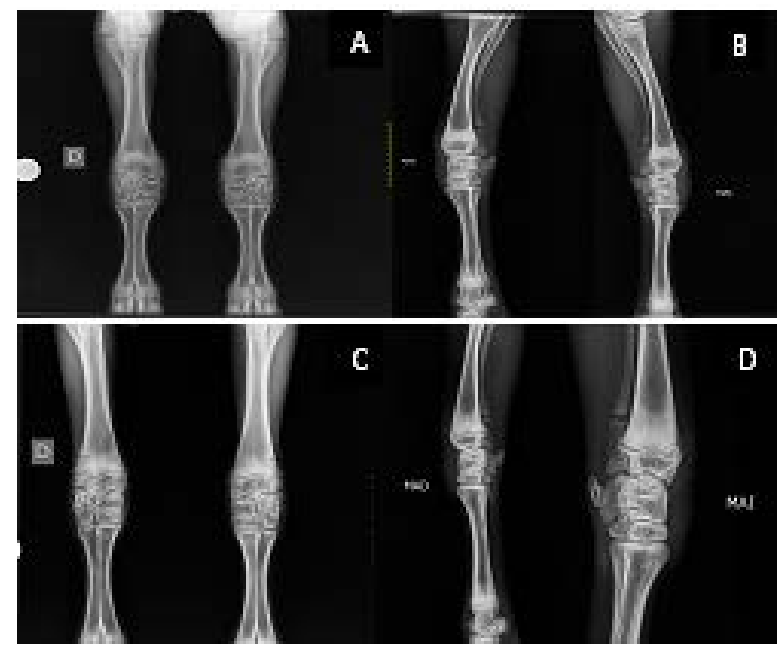

Figura 1. Placas radiográficas tomadas a los 72 días de edad (A-C: incidencia antero-posterior; B-D: medio-lateral) de los miembros anteriores del animal control y de uno de los animales tratados con enrofloxacina, respectivamente.

Además, clínicamente dos animales presentaron signos asociados con una alteración articular (inflamación, restricción de actividad, decaimiento), la cual fue reversible clínicamente luego de la suspensión del antibiótico (resultados no mostrados).

En un estudio similar realizado en corderos, utilizando la misma droga a razón de $5 \mathrm{mg} / \mathrm{kg}$ (grupo terapéutico) y $35 \mathrm{mg} / \mathrm{kg}$ (grupo tóxico) durante 15 días, los investigadores no evidenciaron cambios clínicos para ningún tratamiento, y sólo encontraron alteraciones histopatológicas en los cartílagos correspondientes a los animales del grupo tóxi$\mathrm{CO}^{5}$.

En conclusión, se observa que el uso de enrofloxacina, bajo este esquema de administración, tuvo un efecto negativo en las articulaciones de los animales que lo consumieron. Las lesiones se visualizaron a partir del análisis de las imágenes radiográficas, acompañadas por una alteración clínica del animal.

Por tratarse de una experiencia piloto, se recomiendan estudios que profundicen sobre la dosis adecuada para la utilización del compuesto en la especie caprina y la formulación de recomendaciones para elaborar un protocolo adecuado de administración.

Agradecimientos. Al Consejo Nacional de Investigaciones Científicas y Técnicas (CONICET) y a la Universidad de Buenos Aires, por el financiamiento para la realización de este trabajo.

\section{REFERENCIAS}

1. Babaahmady E. 2011. Toxicology of baytril (enrofloxacin). African J Plant Sci 5: 2042-2045.

2. Bearson BL, Brunelle BW. 2015. Fluoroquinolone induction of phage-mediated gene transfer in multidrug-resistant Salmonella. Int J Antimicrob Agents 46: 201204.

3. Ebert I et al. 2011. Toxicity of the fluoroquinolone antibiotics enrofloxacin and ciprofloxacin to photoautotrophic aquatic organisms. Environ Toxicol Chem 30: 2786-2792. 
4. Khazaeil K et al. 2012. Enrofloxacin effect on histomorphologic and histomorphometric structure of lamb articular cartilage. Glob Vet 9: 447-453.

5. Rao GS et al. 2002. Disposition kinetics of enrofloxacin and ciprofloxacin following intravenous administration of enrofloxacin in goats. Small Rumin Res 44: 9-15. 